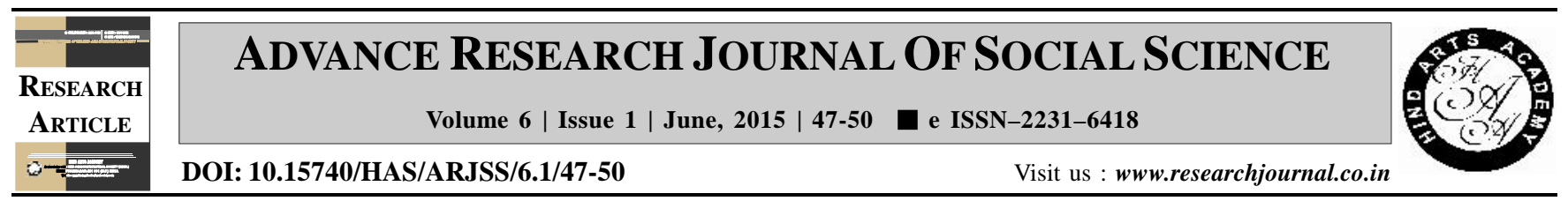

\title{
A study on knowledge of health care practices among rural women
}

Mohini Saxena

Department of Home Science, Ginni Devi Modi Girls P.G. College, Modinagar, GHAZIABAD (U.P.) INDIA

(Email: moheene.sexena24@gmail.com)

\section{ARTICLE INFO :}

$\begin{array}{lll}\text { Received } & : & 12.02 .2014 \\ \text { Revised } & : & 19.04 .2015 \\ \text { Accepted } & : & 01.05 .2015\end{array}$

KEY WORDS :

Health practices, Rural women, Knowledge

\section{HOW TO CITE THIS ARTICLE :}

Saxena, Mohini (2015). A study on knowledge of health care practices among rural women. Adv. Res. J. Soc. Sci., 6 (1): 47-50.

\begin{abstract}
The present study was conducted to know the knowledge of selected health care practices among rural women. In the study a total of 200 women were selected by simple random sampling. Women respondent knowledge on adolescent health care revealed that they had almost full knowledge on personal Hygiene, use of clean cloth or sanitary pad during menstruation and seeking medical help in case of improper menstruation. But nearly 20 per cent of them did not have adequate knowledge on the issue of providing adequate information to their girl children, before they start menarche. The results of motherhood and intranatal care revealed that about 90 per cent of respondents had almost full knowledge an antenatal medical check-ups, taking two tetanus toxoid injections during the pregnancy, taking iron and calcium tablets and awareness of intranatal care. About 27 per cent of rural women did not possess adequate knowledge of the balanced nutrition diet and adequate rest for the pregnant women for safe motherhood and delivery. The results of new baby care revealed that 20 per cent each of the rural women respondents did not possess adequate knowledge of the importance of breast feeding, especially collustrum immediately after birth and continuously breast feeding the child up to two years for adequate nutrition to the infant child. The results of family planning method revealed that 85 per cent of rural women had knowledge on the ideal age of women at their first pregnancy and the significance of timing births and adopting ideal spacing between births for their better reproductive health. Only 68 per cent of rural women were aware of the actual size of ideal family. One disturbing result of the study was that nearly 54 per cent of rural women respondents were not aware of the risks and dangers involved in late age (beyond 35 years) pregnancies and in having fourth or fifth pregnancy.
\end{abstract}

